\title{
A Study of Wolf Culture from Multi-perspectives
}

\author{
Furui Jia \\ College of Liberal Arts \\ Northwest University for Nationalities \\ Gansu, Lanzhou, China 730030
}

\begin{abstract}
In human culture, the wolf is often regarded as a symbol of "cruelty" and "barbarism", but with the development of the times, the wolf' image is also changing quietly. In the past twenty years, more and more diversified expression forms of wolf culture have been found. This paper studies the change of wolf image from the perspective of literature, song, film and television works, and uses different visual angles to explore the connotation of wolf culture.
\end{abstract}

\section{Keywords—wolf; wolf culture; change}

\section{INTRODUCTION}

In 2004, Jiang Rong's novel "Wolf Totem" started on sale, this book has become a best-selling book swept the country since then, and later made into a film, the heat is not reduced. Jiang Rong's "wolf" image subvert people's perception of wolf in the past, attract people's attention, the academia began a crazy wave of "wolf" study. Throughout these 20 years, wolf as a special image, frequently appeared in literature, film and television works, advertisements and songs, its influence can not be underestimated, this paper from several aspects to study the change of wolf image and its cultural significance.

\section{WOLF CULTURE IN LITERARY WORKS}

\section{A. "People Wolf Confrontation": Since Ancient Times the Image of Wolf in People's Minds}

Yan Lianke published "Year Month Day" in 1997, created an image of old farmer Xian Ye who guard his home alone in dry days, struggle with nature in extreme predicament again and again. Although the "Year Month Day" is not specifically writes about wolf, but in the performance of the old farmer's living will and life force in famine year, it used a large length to write the confrontation conflict between the old man and wolf. Such confrontation can be regarded as one of the most classic and most representative confrontation description among contemporary wolf theme novels. Confrontation two sides- Xian Ye and yellow wolf pack, the reasons for confrontation - compete for water, the result of confrontation Xian Ye get rid of wolf pack successfully. "Stalemate like a bridge ride on the sight of Xian Ye and the wolf king, each blink of their eyes, that stalemate come up with some startling sound, Xian Ye felt the sore of his legs stinging thorns his body. Stalemate is consuming his physical strength with dozen times heavier than the daily labor, the cold sweat from his feet is wetting his soles, he felt his both feet seem like stepped on two pools of cold water ... time was like the silent old cow pulls, slowly rolling on Xian Ye's willing in the stalemate." ${ }^{1}$ After a long confrontation, the wolf pack retreat, Xian Ye survived. This work made people feel excited on the depiction of the old man's perseverance and his final victory.

People and wolf confrontation scenes are common in many literary works, such as the conflict between people and wolves in Guo Xuebo's novel "Male Wolf". In this novel, the person and wolf confrontation plot throughout the whole book. At first, the hunters from Shatuozi caught the unattended wolflings in the wolf cave under the leadership of village mayor, and cruelly killed a few wolflings, the male and female wolf return back to the wolf cave but found their children's tragic death so they began the crazy revenge to human. The villagers set up a trap in the panic, the male wolf was trapped, the iron clip caught one of its leg so it can not escape. "The male wolf moving again, dragging the iron clamps and chains more violently, try to get rid of the stumped wooden posts .When the villagers get closes to the male wolf with sticks, male wolf showed its teeth with a howl and jump highly toward to the close villager. The man soon returned to escape, and dropped down on the ground, fortunately the ion chain dragged male wolf back. None of the villagers dare to approached, they just surround it and shouting." ${ }^{2}$ In this confrontation between people and wolf, it describes people and wolves in contrast, making people as a reference point for the wolf, further sets off for the wolf image by contrast.

\section{B. "Miss the Wolf": Reflections on Wolves under Ecological Consciousness}

In the 90s, China's economy began to develop rapidly, the consequent ecological and environmental problems have also attracted people's attention. In the ecological environment, the "natural enemy" relationship between wolf and human makes "wolf" this ancient species gradually becoming endangered, and the narration about it in literary works is necessarily related to "ecological literature". During this period, the ecological consciousness strengthening is also an important reason for the rapid development of wolf theme novels.

"Miss the Wolf" is Jia Pingwa's work which published in 2000 , the novel uses a unique perspective, tells the archival experience of hunters and reporters photographed the Shangzhou surviving fifteen wolves. The blood disaster, Jin Xiangyu of China, the trail of wolves, horrors of the ancient

\footnotetext{
${ }^{1}$ Yan Lianke. Year Month Day" [J].Harvest,1997,(1).

2 Guo Xuebo. "Male wolf” [M]. Beijing: China Youth Publishing Company, 2009.
} 
battlefield, the reporter's illusion, the wondering of animals' souls, meat Ganoderma lucidum and other events make reader fell scandalized, filling with the author's uninhibited writing style and rich imagination. Jia Pingwa's "Miss the Wolf" for the first time raised the cultural reflection on Shangzhou up to the worries and early warning of the whole human being's living and fate. The environmental ethics consciousness and the ecological ideals for the harmonious coexistence of human and nature gave a very high ideological value to this novel. "The novel in the theme layer of 'search', 'miss the wolf' means 'miss the hero' and 'miss the blooming life', in the ecological theme level, 'miss the wolf' is 'miss the balance of the world' and call for the ecological ideal of 'harmonious coexistence between man and nature'".

In recent years, there are many works are from the perspective of the ecological to conduct "Wolf" Reflection: in "Wolf Nature in Plateau"2, at the desolate Gobi during the abnormal years, the wolf was disappeared, but the wolf nature has breed from people's hearts; the village mayor in "Wolf Child in Desert" ${ }^{3}$ killed the whole family of the female wolf, so that make the wolf homeless, human's recklessly reclamation destroyed ecology and attracted sandstorms; "Wolf Totem" ${ }^{4}$ regards "Grassland" as a mirror of human and nature live together, pay high tribute to the wolves who protect the grassland ecological balance; "Tibetan Mastiff" ${ }^{5}$ expresses the concern about the plateau ecological imbalance brought by the wolf killing movement and the Tibetan Mastiff's life become weak; "Wolf Disaster" issued a mournful sign of "no wolf, the land is also a sand ball" ${ }^{\prime}$.Thus, the protection of ecological environment is important, but the protection of wolf packs can not be ignored as well.

\section{C. "Totem of the Wolf": Human Subvert the Traditional Attitude to Wolf}

In 2004, the grassland wolf described in Jiang Rong's "Wolf Totem" pushed the wolf culture to a climax. It impacted on our visions with a brand new image which subvert traditions: it is brave, tough, wisdom, bloody, warm, fight to the death for their own dignity.

"Wolf Totem" wrote a wisdom wolf. Wolf's wisdom is expressed in their hunting activities which borrowed weather and geography advantages. They are good at dormant standby, for the prey it must hit at once. The novel begins with a description of a battle for a wolf pack rounded up gazelle. In the Ereen grassland, there is a windward grass slope about twenty or thirty miles, it is the alternate pasture for local herdsmen in winter disaster. Gazelle group is confused by the

\footnotetext{
${ }^{1}$ Wu Jingming. "Miss the wolf": ecological thinking of human survival dilemma [J].Wenyi zhengming, 2011

${ }^{2}$ Liu Hantai. "Wolf nature in Plateau" [M]: China Workers Publishing Company, Beijing, 2001.

${ }^{3}$ Guo Xuebo. "Wolf child in desert" [M]: China Federation Art Circles Publishing Company, Beijing, 2001.

4 Jiang Rong. "Wolf Totem" [M]. Wuhan: Changjiang Literature and Art Publishing Company, 2004.

5 Yang Zhijun “Tibetan Mastiff” [M]. Beijing: People's Literature Publishing Company, 2005.

${ }^{6}$ Xue Mo. "Wolf disaster" [M]. Beijing: China Federation Art Circles Publishing Company, 2001,31.
}

snow storm they are hungry and cold so they rushed into this pasture desperately, and the wolf pack at this time quietly surrounded the gazelle group from three sides. Wolves use the snow nest terrain, control temporary hunger and greed, waited until the gazelle group eats too much and unable to run, the wolves suddenly attacked from three sides, the vast majority of gazelles will fall into the snow nest and became the wolf's food. Novel described in heavy colors on the second battle of wolves, when the outsiders emptied wolf's stored gazelle meat under the snow, the wolves did not eager to take revenge action, but patiently waiting for the opportunity to kill at one strike. In addition the wisdom of the wolf is also reflected in the use of otter hole as wolf cave, catch otters, imitation of small animals to attract pony and such behaviors, even the wolfling who left the wolf pack before open his eyes, it could dig a cool and self-defense hole to avoid heat and people in the hot summer without a teacher. Wolf's wisdom is so amazing.

"Wolf Totem" wrote a wolf full of maternity. In order to protect the wolflings, wolf pack will use the highest intelligence and wolf's special skills, especially those female wolves, "in order to teach wolfling hunting, female wolves often risk catch alive lambs; in order to protect the wolflings in the cave, they will fight with hunters until death; for the safety of the wolflings, they often dangling wolflings transfer to another cave overnight ; in order to feed the wolflings, they often eat too much until almost broke belly, and then spit all the food from belly to wolflings; for the common interests of wolf family, those female wolf who lost the whole nest wolflings will feed the wolflings from her sisters or cousins..." Maternal love is the most sincere human emotions, and for the Mongolian wolf, this emotion is well revealed.

"Wolf Totem" wrote a doughty wolf. The indomitable spirit of prairie wolf was formed from the long term brutal living fighting with other animals in the grassland. There is a fragment of the novel is frightening, and that battle of wolf pack round up hunting army horses reflected the wolf's doughty spirit: "Prairie wolf uses the most cruel, most bloody, most incredible means to launch a group attack to the horses. The big wolves, especially those who female wolves who lost their wolflings, jumped up crazy, penetrate the thinnest belly on rib side with one bite, and then dragged with its own weight, at the expense of its lower half body hung on the side of the horse heavily ... ${ }^{8}$ After the army horses were annihilated, the herdsmen conducted a retaliatory strike on the wolf pack. In such a harsh battle conditions, the wolf placed in death still maintain their reason, they used a cruel tactics: use light wound for serious wound, use heavy injury for enemy life, set their own wounds in disregard, attack dog's throat and stomach violently. When army representative Bao Shungui lead his troops to chase two strayed old wolves, the male wolf in the hopeless situation of three sides cliffs and one side connected to steep slope, ran into the steep slope side and buried itself under the numerous break stones and rolling sand; Female wolf collapsed the cave from inside and buried itself alive,

\footnotetext{
7 Jiang Rong. "Wolf Totem" [M]. Wuhan: Changiiang Literature and Art Publishing Company, 2004,257.

${ }^{8}$ Jiang Rong. "Wolf Totem" [M]. Wuhan: Changjiang Literature and Art Publishing Company, 2004,49.
} 
even a complete skin was not left to human. This "better to die in glory than live in dishonor" spirit is so heroic.

The wolf's wisdom, tenacity, tenderness, indomitable spirit and Mongolian's reverence and devout worship to the wolf in "Wolf Totem" let us to re-understand wolf this animal, such spirit they have shocked us.

\section{WOLF CUlture In SONGS}

In wolf culture this diversified expression form, song is also an important art form. The early Qi Qin's classic works "Wolf", Alan Tan's "Wolf in Sheep Skin ", in recent years Tang Chao's "Wolf in Love with Sheep" and other songs, have been widely spread. The domestic animation "Pleasant Goat and Big Big Wolf" broadcast made the "Big Big Wolf" image known to every family, and also led the development of related industry chain. The songs related with "Pleasant Goat and Big Big Wolf" "Marry to Big Big Wolf" and "If marry then marry to Big Big Wolf" swept the country. However, in these wolf songs, the interpretations of wolf are not the same, the image of the wolf continue to enrich with the development of times.

\section{A. "Wolf Is Coming" - Ungrateful, Cunning Wolf Image}

"Wolf is coming" story can be considered as the enlightenment of human to understand "wolf culture", it warned children: If lying, will be eaten by wolves. In the contemporary lyrics can also find "wolf is coming" songs. Some of the songs directly named "wolf is coming", such as Yang Qianhua's "Wolf Is Coming", Zeng Guohui's "Wolf Is Coming", Wang Wanzhi's "Wolf Is Coming", Yang Chenglin's "Wolf Is Coming" and so on. Yang Chenglin's "Wolf is coming" said: "You said wolf is coming, you said you still love me, playboy dead, heart is changeable, I said wolf is coming, who will be the next victim ". The lyrics described the woman knows the man is a master of lying, but she is still been cheated. The woman did not blindly chasing him, but release him freely, and also warned the next victim not to be cheated by false love. In this song, the "wolf is coming" refers to the people who is unfaithful to love.

In most of these songs, "wolf is coming" refers to men hurt women in a relationship and make women suffering, but men is cunning like a wolf and in the same time is unfaithful to love. This image of wolf is the evil image that it always has, its image has not changed.

\section{B. "I Am A Wolf from the North" - Lonely, Wandering Wolf Image}

In 1985, Qi Qin's "Northern Wolf" came from the wilderness, "I am a wolf from the north, walking in the vast wilderness, the mournful north wind blowing, yellow sand all over the sky, I could only bite the cold teeth, making one to two long howls, not for anything else, only for the legendary beautiful prairie". The author of this song Qi Qin gives the new life characteristics for the northern wolf: loneliness, cold arrogance, wandering, unyielding, melancholy and persistent. This lonely image deeply rooted in people's minds in the $80 \mathrm{~s}$, directly crash people's spirit. In addition, Qi Qin also created two songs about the wolf "Seven Wolves" (2002) and "Ya Kou" (2005), "Seven Wolves": "deep-set steps never tamed, dressed like a gentleman is the treble of love, the speed of the myth, the wild has been tamed, look to the farthest, if you encounter another wolf, it is only attracted to its loneliness, still look to the farthest, the farthest of that beautiful grassland. This wolf lost grassland, had to deep-set in the urban jungle. With the development of modern society, meaning the wild and passion in human are also gradually disappear. Loneliness and tameless are also the wolf's nature. Look at "Ya Kou", a wolf looking at the moon at the intersection of two mountains, enjoying the baptism of the wind, the wolf has always chase and explore the meaning of life with the gesture of a free wolf. Ii said: "They said I was originally a wolf, once lost in the troubled years, singing a song called life, but I do not know what life is". In the songs the wolf is lonely, stubborn and confused, find the true meaning of life in the uneasy years to, which meet the spiritual characteristics of the times.

Qi Qin sung the voice for the people at that time with the tone of wolf, gave the wolf human's lonely and wandering spirit features. In this period, in addition to Qi Qin's "Northern Wolf", as well as Wang Chengfei's "Southern Wolf". Whether "Southern Wolf" or "Northern Wolf" has "lonely" characteristics, such as the "Southern Wolf", for which Wang Chengfei wrote lyrics and sung, it said: "I am a wolf from the South, without ferocious and rough, I keep running and wandering in bustling city, I am alone and confused in lonely wilderness, I am a wolf from the South, too much passion too much sad, I filled with gentle sadness in the love sea, I look for the legendary sheep in the vast sea of people". The wolf faded all the "ferocious", "rough" and "passion", but showed loss, loneliness and tenderness. We can see the wolf characteristics expressed in lyrics are the characteristics which all modern city people held, and also the mapping of modern people's confused and lonely psychological state.

\section{C. "Wolf in Love with Sheep" -the Wolf Image which Change Its Nature for Love}

Through the lonely of Qi Qin's "I Am A Wolf from the North", we ushered the heart-broken love story about wolf in love with sheep. As we all know, wolf and sheep are born natural enemies, wolf eat sheep is the law of nature. However, in the contemporary lyrics, wolf and sheep appeared as a couple. "Wolf in Sheep Skin" is a song released by Alan Tan in 2004, "I'm sure I'm the wolf in sheep skin, and you're my prey, you are the lamb in my mouth. I left other wolves wandering alone, just because I am unwilling to share you with others, I am sure this life I will be beside you, with a fiery heart to go any place with you". With Alan Tan's lovingly interpretation, this "Wolf in Sheep Skin" is quickly popular in China. And regardless of the melody of this song, only the lyrics is novelty enough, compared lover as sheep and himself as the wolf in sheep skin, where the wolf is not cruel, ungrateful such traditional wolf, and it is not alone, tameless, persistent wolf. This type of wolf tried so hard to change its nature, willing to change himself into a gentle sheep, and ultimately achieve the purpose of fall in love with the sheep.

Wolf in contemporary lyrics became a sheep, indicate that the roles of wolf and sheep are interchangeable, and the status of wolf and sheep are also undergoing major changes. If, in Alan Tam's "Wolf in Sheep Skin", the "wolf" sill implicitly 
dressed in sheepskin for "sheep", but Tang Chao's "Wolf in Love with Sheep" issued in 2006, the wolf simply remove the camouflage and directly into battle: "Wolf fell in love with sheep, love crazy, they are in a true love. Wolf fell in love with sheep, it is not absurd, they said there will be a direction as long as they have love. Wolf fell in love sheep, love crazy, they pierced the secular walls, wolf fell in love sheep, crazy love, they held each arm to far away". Lyrics depicted after a wounded wolf saved by a sheep, it fell in love with the sheep. The lyrics also wrote that they want to be together forever, we must break the secular walls. We can see that the role and status of wolf and sheep in the contemporary lyrics have a fundamental change. If wolf and sheep love want to be become reality, then wolf must make concessions, and to change its own habits even its nature to cater to the "sheep". Obviously, the wolf was assimilated by the sheep.

\section{D. "If Marry then Marry to Big Big Wolf" - Wolf Image of Hard Working Good Husband in New Era}

The hit of Cartoon movie "Pleasant Goat and Big Big Wolf" brought Big Big Wolf into the public eye. Big Big Wolf is super popular, it was loved by children from the animated cartoon angle, and it has been sought after by adults by the performance of the ideological content, especially women consider it as the role model for new good man who did housework cook and also good at coax his wife. Songs created based on this role also have a high recognition value in public. Ya Feng's song "Marry to Big Big Wolf" (2009) said: "marry to Big Big Wolf, he will put you on his heart, he will get starts and moon for you, he will fly with you with love. Marry to Big Big Wolf, he will cherish your love forever, he will go crazy only for you, he will stay with you with no regrets, stupid wolf, Big Big wolf, he catch the lamp for you with his entire life". The "Big Big Wolf" in the song are hard-working in family, be all obedience, always in love with his wife, in full compliance with the requirements of a good husband for modern women. At the time the Big Big Wolf is no longer the representative of evil, it carries the beautiful expectations of modern women.

Let us see Zhou Yanhong's "If Marry then Marry to Big Big Wolf"(2011), it said: "If marry then marry to Big Big Wolf, this man is a role model, a woman is like a flower can not afford storms, at most with a little thorn and rose incense. If marry then marry to Big Big Wolf, this kind love is right, you are my wall to shield wind and frost, I am your treasure for a while life". Zhou Yanhong's song sung out the voice of young women nowadays, the work pressure of young people is very large, personal space is also very narrow, they are very eager to be cared by love, especially women are eager to have a Big Big Wolf-style good man around to tolerant and adore them. At the time Big Big Wolf has completely became a good image in people's hearts.

\section{IV. "WolF" Culture In The FILM AND TELEVISION WORKS}

In recent years, there are many films and television works also appeared wolf culture. And regardless of the main content of film and television works, only from their names there are many with the word "wolf", such as "Lone wolf", "Blue Wolf", "Battle Wolf" "Snow Wolf", "Wolf Poisonous Flower", "White
Wolf", "Snow Wolf Valley", "Dance with Wolves", "Shoot the Sky Wolf", "Kill Wolf Flower", "Wolf Smoke", "Wolf Hunting", "Wolves in the Desert" and so on. These films and television works are mostly military and revolutionary themes, and through the interpretation of the content of these films and television works, we found "wolves" in these works are half good half evil, these "wolves" are not wolf from a true sense, they are a symbol, they are invisible, representing a spirit or some kind of suggestion. The reason is, as people have good and evil, wolves also have good and evil, these films is nothing more than given the wolf's half good half evil nature to fresh characters from the artistic point of view and humanize the "wolf nature".

\section{A. "Wolf" Is the Designation of Hero}

Wolf such vicious animal, once they fiercely pegged to a goal, they will persevere. Wolf represents a team spirit, a innovated spirit and tenacious fighting spirit are more prominent. In the military theme and revolutionary theme works, a special force or some detachment always designated as "wolf", such as the "Lone Wolf Commando in TV series "I Am A Special Forces", the "Blue Wolf Commando" in "Blue Wolf" and so on. Also a single commando is also known as "Timber wolves", "Lone wolf", "Snow Wolf" and the like code. This "wolf" troops way will add a mystery sense and brought fear to the enemies. In this kind of film and television works, the described people is Chinese outstanding bloody male groups, they are "the wolf of justice" who aggressively, bravely, toughly and strongly defenses their territory.

This kind of film and television works transplanted "wolf" into the characters' character, embodied the nature of characters and the representability for such subject matter. Such character in order not to be bullied, usually use violent means to achieve their own purposes, they are vicious and cruel, "deal with a man as he deals with you". But in some red spirit films, they also demonstrate their spirit of "While the universe keeps rolling on orbit, a superior man makes untiring endeavor for advancement", such as the hero Chang Fa in "Wolf Poisonous Flower", he changed into a real hero from a freebooting hero because he as this "Wolf" character in him.

TV series "I Am A Special Forces", in the performance of the special forces' character quality, through the reference of a large number of combat techniques which owned by animal wolf nature to highlight the wolf nature of these soldiers. These special forces were trained like "wolves", in combat, they have their own organizational discipline and their own unique set of rules, they check out the location, ambush, attack, intercept like a wolf, fast but without reckless. Among them, the most amazing is team spirit reflected in the battle, they are not brothers but closer than brothers, training and fighting every day, sometimes they are willing to sacrifice their lives to win. The characters' quality expressed in the TV series "I Am A Special Forces" are borrowed from the animal wolf. The playwrights have integrated it into the military's operational system and sublimated it, so as to achieve the fullness of the characters' character. The "Wolf nature" embodied in this type of works could express the distinctive characteristics of the characters and enrich the works, so that the audience feel more exciting during watching. 


\section{B. "Wolf Dressed in Human Skin"}

Until now, in people's hearts, the wolf has always been brutal. If we meet a wolf in the forest, it means we are not far from death. Wolf's negative emotions deeply rooted in people's hearts. There are many related proverbs and idioms have been circulating so far, such as "Langxin goufei", "Langbei weijian", "Langzi yexin", "Yinlang rushi", "Se lang" and so on. "Wolf" besides to regard as the hero's designation, in some film and television works the "wolf" is nothing more than the description of all kinds of "Wolf dressed in human skin" in social life. In a word, because of its brutal, cunning and greed, the wolf has always been a natural enemy of mankind as the role positioning in traditional Chinese culture. It is a negative cultural plasticity which been rejected and denied by human. Therefore, the images that highlight the evil character of "wolf nature" are common in film and television works.

In a lot of spy and revolutionary theme films and television works, some of the enemy organizations, ruffians and ruthless villains are known as the "wolf." These "wolf" titled film and television works always make the audience vaguely feel the crisis of "eaten by the wolf", make people naturally associated with the Oriental wolf who deliberately intrude into our courtyard and brought a huge trauma and damage to Chinese nation. Their ferocious, inhumane side was the combination of all the notorious "cold-blooded" natures which wolf possessed, and the wolf's wickedness transferred into the characters who "dressed human skin but act like a wolf. This means of expression easily make people to connected bad people with evil wolves and reached the effect of "human and wolf together in one", which make the characters in film and television works with more flesh and blood. For example, the TV series "Dance with Wolves", the show began with the story of full liberation of the Northeast China and the Liaoshen campaign's complete victory, after the spy of our party Chen Shaojie finished his mission in the northeast battlefield, he went to the southwest alone and spied in the "Wolf lair "Southwest General Administration, it described he and Kuomintang secret agents fight with wisdom and courage, tenacious fighting and start his own hidden mission. The show not only expressed the enemy's cunning and prudent side, but also expressed their ferocious and dangerous side. Displayed the pros and cons in "wolf nature" and the complexity of "human nature" so that to make the character image more perfect.

In recent years, in the film and television work fields, the spy films and military films titled with "wolf" emerged in an endless stream. From the artistic perspective to make vivid interpretation, transfer the "wolf spirit" into human spirit and make a perfect combination of human and wolf, this art performance means is a sublimation after the in-depth understanding of wolf image, so that to make the characters in the film and television works more plentiful and the story more exciting.

\section{CONCLUSION}

As a unique and popular cultural image, "wolf" has attracted more and more attention. It not only entered into the literary perspective, but also appeared in various aspects of social culture, such as the songs, film and television works mentioned in this paper. Wolf image showed in this different cultural forms is not changeless, with the development of the times, it is given a variety of different images by human in order to express people's reflection and introspection for present society.

\section{REFERENCES}

[1] Yan Lianke. "Year Month Day"[M]. Zhengzhou: Henan Literature and Art Publishing Company, 2010.

[2] Guo Xuebo. "Male wolf" [M]. Beijing: China Youth Publishing Company, 2009.

[3] Liu Hantai. "Wolf nature in Plateau" [M]: China Workers Publishing Company, Beijing, 2001.

[4] Guo Xuebo. "Wolf child in desert" [M]: China Federation Art Circles Publishing Company, Beijing, 2001.

[5] Jiang Rong. "Wolf Totem" [M]. Wuhan: Changjiang Literature and Art Publishing Company, 2004.

[6] Yang Zhijun "Tibetan Mastiff" [M]. Beijing: People's Literature Publishing Company, 2005.

[7] Xue Mo. "Wolf disaster" [M]. Beijing: China Federation Art Circles Publishing Company, 2001.

[8] Wu Jingming. "Miss the wolf": ecological thinking of human survival dilemma [J].Wenyi zhengming, 2011 